\title{
The Effect of Gadolinium on the Microstructures and Charpy Impact Properties of Super Duplex Stainless Steels
}

\author{
Byung-Moon Moon ${ }^{1,+}$, Sang-Wook Lee ${ }^{1,2,+}$, Moon-Jo Kim ${ }^{1}$, Seung-Rok Jung ${ }^{1,2}$, \\ Young-Jig Kim ${ }^{2}$ and Hyun-Do Jung ${ }^{1, *}$ \\ 1 Liquid Processing \& Casting Technology R\&D Group, Korea Institute of Industrial Technology, \\ Incheon 21999, Korea; moonbm@kitech.re.kr (B.-M.M.); liolio@kitech.re.kr (S.-W.L.); \\ moonjokim@kitech.re.kr (M.-J.K.); jsrbasket@kitech.re.kr (S.-R.J.) \\ 2 School of Advanced Materials Science and Engineering, Sungkyunkwan University, Suwon 16419, Korea; \\ yjk1122@skku.edu \\ * Correspondence: jhd1357@kitech.re.kr; Tel.: +82-32-850-0437 \\ + The two authors contributed equally to the work described.
}

Received: 21 May 2018; Accepted: 19 June 2018; Published: 21 June 2018

\begin{abstract}
Super duplex stainless steels (SDSSs), exhibiting excellent strength and corrosion resistance, serve as the attractive materials in a variety of industries. However, improvements in their ductility and impact-toughness are required in extreme environments. In this study, the effects of gadolinium on the microstructures and Charpy impact properties of super duplex stainless steels were investigated. A base super duplex stainless steel (BDSS) and a gadolinium-added super duplex stainless steel (GDSS) were successfully fabricated using an air casting method. The oxygen content and grain size of SDSSs were found to decrease because of high reactivity of gadolinium with oxygen. Moreover, the average inclusion size and area of GDSS also decreased even with a slight decrease in the average distance between inclusions. Both the BDSS and GDSS exhibited typical Charpy impact transition behavior from $-196{ }^{\circ} \mathrm{C}$ to $200^{\circ} \mathrm{C}$. Moreover, the GDSS impact energies using Charpy test were higher than those of BDSS over the entire temperature range. Moreover, the ductile-to-brittle transition temperature (DBTT) of SDSSs calculated from the fracture appearance transition temperature (FATT) significantly decreased by over $20^{\circ} \mathrm{C}$ with the addition of gadolinium.
\end{abstract}

Keywords: duplex stainless steel; gadolinium; Charpy impact properties; microstructure; inclusions; grain size

\section{Introduction}

Recently, rare-earth metals (REMs) have been widely used in various materials to improve their performance or change their functionality [1]. A small addition of REMs in the materials can cause important changes in the properties of the materials. REM (such as, ceria and lanthana)-based compounds are receiving increasing attention due to their automotive exhaust catalyst applications, high oxygen storage capacity and larger ionic size [1-3], which result in a significant enhancement of the catalyst performances. A major application of REMs is remarked in the luminescent materials, such as phosphors [4-7]. REMs can also be used as additives in cast metals to improve their microstructures and mechanical properties. However, when they react with harmful non-metallic inclusion-forming elements, such as nitrogen, oxygen, and sulfur, they can modify $\mathrm{MnS}$ or $\mathrm{MnO}$, resulting in the formation of stable REM compounds, such as $\mathrm{REMO}_{x} \mathrm{~S}_{y}$ [8-11]. Some researchers reported that the addition of REMs improved the mechanical properties of iron and steel by changing the graphite and sulfide morphologies, respectively [12-15]. Additionally, REMs can reduce the grain size of cast metals, 
influencing the strength and toughness of the metals $[9,16]$. Using REMs for various applications in the plant, automotive, and aerospace industries, attempts have been made to fabricate high-quality cast metals.

Gadolinium (Gd), a specific type of REM with high neutron-absorbing ability, is commonly used in medicine to target tumors. Recent studies have also demonstrated its applications as a neutron-absorbing material which can be used in shielding of nuclear fuels in nuclear reactors $[1,17]$. Some researchers also identified $\mathrm{Gd}$ as a metal additive. Using a metal injection molding (MIM) method, Holm et al. fabricated Ti-6Al-4V alloys with 1-5 wt. \% Gd [18]. The ability of Gd to reduce the grain size, change the residual pore size and shape after sintering enhances fatigue behavior. Ghandvar et al. fabricated an $\mathrm{Al}-15 \% \mathrm{Mg}_{2} \mathrm{Si}$ in situ composite by adding Gd [19]. Typically, Gd was an important component that caused the formation of small $\mathrm{Al}_{3} \mathrm{Gd}$ particles, which acted as the heterogeneous nucleation substrates for $\mathrm{Mg}_{2} \mathrm{Si}$, thereby modifying the composite's macrostructure. Despite the outcomes of these pieces of research, only a limited number of studies investigated Gd as an additive use. Therefore, there is a need for more in-depth studies to understand the effect of Gd as a REM additive.

Stainless steels are one of the most commonly used metals across industries. Many different types of stainless steel are classified by their main phase and characterized by their various applications [20-22]. Ferritic stainless steels with high chromium, and low carbon contents exhibit good corrosion resistance and stress corrosion cracking with relatively low ductility [23-25]. Austenitic stainless steels, referred as non-magnetic steels, are characterized with good workability, high toughness, weldability and plasticity. However, they are vulnerable to localized corrosion in chloride-rich environments [26-28]. On the other hand, duplex stainless steels, comprising both ferrite and austenite phases, have received a great attention owing to their excellent corrosion resistance and mechanical properties [29-31].

Super duplex stainless steels (SDSSs) are a family of duplex stainless steels (DSSs) with a high pitting resistance equivalent number (PREN) over 40 [32,33]. SDSSs have much higher corrosion resistance than other DSSs, and thus, they are widely used in severe industrial environments, such as in the petroleum, nuclear reactor, and sea-plant industries [21,34]. Thus, their mechanical properties in the actual environment are quite important to ascertain the reliability of SDSSs under high-and low-temperature conditions [35]. Particularly, the impact toughness of SDSSs under extreme temperatures is important for the safety and long-term reliability of cryogenic machinery [36-38].

The purpose of this research is to investigate the influence of $\mathrm{Gd}$ on the microstructures and Charpy impact properties of SDSS. A890 grade 7A super duplex stainless steel was used and $0.1 \mathrm{wt}$. \% of Gd was added and formulated for casting. Moreover, electron backscatter diffraction (EBSD) and field-emission scanning electron microscopy (FE-SEM) were carried out to investigate the microstructures and inclusion of the fabricated alloys. The phases and compositions of the alloys were characterized by X-ray diffraction (XRD) and energy-dispersive X-ray spectroscopy (EDS). The mechanical properties were examined using Charpy impact tests carried out at a different of temperatures.

\section{Materials and Methods}

\subsection{Materials and Alloy Fabrication}

In this study, all the SDSSs used for the experimental purpose were cast in a high-frequency induction melting furnace (Inductotherm, Rancocas, NJ, USA). The starting materials for SDSS fabrication were high-purity iron $(\mathrm{Fe})$, nickel $(\mathrm{Ni})$, chromium $(\mathrm{Cr})$, manganese $(\mathrm{Mn})$, silicon $(\mathrm{Si})$, ferromolybdenum (Fe-60 wt. \% Mo), and ferrochromium nitride (Fe-60 wt. \% Cr-10 wt. \% N). All metals excluding Gd were melted at approximately $1640{ }^{\circ} \mathrm{C}$. Moreover, $0.1 \mathrm{wt}$. \% Gd granules (1-2 mm, 4N grade, Treibacher industrie AG, Althofen, Austria) were added to the molten SDSSs at approximately $1580^{\circ} \mathrm{C}$ to suppress the oxidation of Gd. The air-cooled cast SDSSs in a sand mold were 
cut into $200 \mathrm{~mm} \times 30 \mathrm{~mm} \times 30 \mathrm{~mm}$ specimens and solution-treated for $2 \mathrm{~h}$ at $1130{ }^{\circ} \mathrm{C}$. The specimens were then quenched in water to avoid secondary phase formation and to achieve an approximate ferrite-to-austenite ratio of 50:50 according to the ASTM A890/A890M standard [39]. The chemical compositions of the fabricated alloys were analyzed using a gas analyzer (ONH-2000, Eltra, Haan, Germany) and inductively coupled plasma optical emission spectroscopy (ICP-OES) (iCAP-6300, Thermo Scientific, Waltham, MA, USA). The results are presented in Table 1. The alloys fabricated without the addition of Gd is referred as BDSS (base duplex stainless steel) while the alloy fabricated with the addition of Gd is called GDSS (Gd-added duplex stainless steel).

Table 1. Chemical compositions of standard A890 grade 7A duplex stainless steel, BDSS, and GDSS (wt. \%).

\begin{tabular}{cccccccccccc}
\hline & Cr & Ni & Mo & Mn & W & Cu & Si & N & O & Gd & Fe \\
\hline Standard & $26-28$ & $6-8$ & $2-3.5$ & $1-3$ & $3-4$ & -1 & -1 & $0.3-0.4$ & - & - & Bal. \\
\hline BDSS & 27.3 & 6.8 & 3.7 & 1.1 & 3.4 & 0.7 & 0.3 & 0.3243 & 0.0692 & - & Bal. \\
GDSS & 26.9 & 6.9 & 3.1 & 1.2 & 3.3 & 0.7 & 0.4 & 0.3157 & 0.0568 & 0.016 & Bal. \\
\hline
\end{tabular}

\subsection{Microstructural Analysis}

The microstructural characterization's specimens were prepared by polishing the surface up to 2000 grit SiC paper and finishing using alumina suspension slurries. The microstructural analyses of the fabricated SDSSs were performed after solution treatment with an optical microscope (ECLIPSE MA200, NIKON, Tokyo, Japan) and the backscattered electron (BSE) detector of a Quanta 200F field-emission scanning electron microscope (FE-SEM; FEI Company, Hillsboro, OR, USA). In addition, electron backscatter diffraction (EBSD; FEI Company, Hillsboro, OR, USA) analysis was used to measure the grain size and ferrite-to-austenite ratio by assuming that Fe-BCC (Body centered cubic) for ferrite and Fe-FCC (Face centered cubic) for austenite exists in SDSSs. All EBSD data was obtained using the following parameters: working distance of $15 \mathrm{~mm}$, accelerating voltage of $20 \mathrm{kV}, 2.5 \mu \mathrm{m}$ step size, and magnification of $\times 55$. The measurement of an area of $4 \times 4 \mathrm{~mm}^{2}$ takes about $10 \mathrm{~h}$. Orientation imaging microscopy analysis, provided by Explorer 4 Analyzer with Metals Quality Analyze (MQA) software, was used in conjunction with the FE-SEM. Three images of each SDSSs were examined to obtain the mean and standard deviation of the grain size and ferrite-to-austenite ratio. The average grain size of each SDSSs was calculated from the measured ratio of ferrite and austenite, and each grain size of ferrite and austenite. The ferrite content was additionally measured using a ferrite scope (Feritscope, FMP-30, Fischer, Achern, Germany) and a ferrite detection limit of $0.1 \%$. Approximately 30 points on each specimen were analyzed. The chemical compositions of the specimens, while observing the microstructures, were analyzed using an energy dispersive X-ray spectroscopy (EDS) attached to the FE-SEM. Furthermore, the phases of the SDSSs were characterized by X-ray diffraction (XRD, D8-discover, Bruker, Germany) with monochromatic $\mathrm{Cu} \mathrm{K} \alpha$ radiation over a diffraction range of $10-110^{\circ}$ at a scanning rate of $0.1^{\circ} / \mathrm{min}$.

The size distribution and average areas of the SDSSs inclusions were analyzed, using a CTR 6000 inclusion analyzer (Leica, Wetzlar, Germany) to analyze 30 points of each specimen. The average areas of the inclusions are reported as a mean \pm standard deviation. One-way ANOVA was used to compare the means of the groups, and the level of significance was $p<0.05$. The average distance between inclusions $\left(X_{0}\right)$ in the fabricated SDSSs is defined as:

$$
X_{0}=0.89 R_{0} f^{-1 / 3}
$$

where $R_{0}$ represents the average radius of the inclusions in the SDSSs and $f$ is the fraction of the inclusions $[40,41]$. It is assumed that the inclusions are spherical and distributed homogeneously in the SDSSs. 


\subsection{Charpy Impact Property Evaluation}

The analysis of the mechanical properties of BDSS and GDSS was carried out using Charpy impact tests, performed following ASTM E23 on V-notched specimens $\left(10 \times 10 \times 55 \mathrm{~mm}^{3}\right)$ at temperatures between $-196{ }^{\circ} \mathrm{C}$ and $200{ }^{\circ} \mathrm{C}$, using a Charpy-type impact tester (SA-ID3, Satec, Union, NJ, USA) [42]. The Charpy analysis was performed on four specimens for each experimental SDSS group to obtain statistically significant results.

The fracture modes of the specimens were analyzed using FE-SEM and EDS. Based on the results from the Charpy impact transition curve, the lower shelf energy (LSE) and upper shelf energy (USE) were determined [43,44]. The ductile-to-brittle transition temperature (DBTT) was calculated with two methods: one was based on the energy transition temperature (ETT), which was the average value of LSE and USE. The other method was based on the fracture appearance transition temperature (FATT) at which the area fractions of the cleavage (brittle texture) to dimple (ductile texture) is 50:50 from the fractured surface of specimens $[45,46]$. The average fraction of shear fracture, obtained from the surface fracture of SDSSs, was analyzed with more than three FE-SEM images for each SDSS reported as mean \pm standard deviation.

The values of impact transition temperature (ITT) were chosen as 27J-ITT and 68J-ITT (corresponding to Charpy impact energy absorption at 27J and 68J, respectively) following the Wallin master curve and ASTM standard in BS 7910:1999 and ASTM E185-82, respectively $[47,48]$.

\section{Results and Discussion}

\subsection{Microstructural Characterization}

ASTM grade 7A SDSS alloys, which mainly comprised of $27 \% \mathrm{Cr}, 7 \% \mathrm{Ni}, 3 \% \mathrm{Mo}$, and $0.35 \% \mathrm{~N}$, were successfully fabricated by casting. Both the fabricated BDSS and GDSS did not show any noticeable voids or cracks, and their chemical compositions matched the targeted composition (ASTM A890 grade 7A) as shown in Table 1 [39]. Moreover, the BDSS and GDSS's PREN values, calculated with the following equation: PREN $=$ wt. $\% \mathrm{Cr}+3.3 \times($ wt. $\% \mathrm{Mo}+0.5 \times$ wt. $\% \mathrm{~W})+16 \times$ wt. $\% \mathrm{~N}$, were greater than 50, indicating an excellent pitting corrosion resistance [49]. The result suggests that both BDSS and GDSS can withstand extreme chemical conditions under the chloride, sulfide, or hypochlorite ion-containing solutions.

Upon addition of $\mathrm{Gd}$, the oxygen content of SDSSs decreased from 692 ppmw to 568 ppmw, which was about $20 \%$ lower. Most research indicates that REMs can deoxidize cast metals, such as steels [50-52]. In this study, we demonstrated that Gd effectively reduced the oxygen content in SDSSs by reacting with oxygen during casting.

Figure 1A,B show the optical micrographs of as-cast SDSSs. Both types of SDSSs, regardless of their Gd's contents, exhibited typical microstructures of duplex stainless steels. The light gray regions in the images correspond to the austenite phase $(\gamma)$, and the dark gray regions correspond to the ferrite phase $(\alpha)$ matrices in BDSS and GDSS. No undesired secondary phases, such as sigma $(\sigma)$ and chi $(\chi)$ phases were detected in both SDSSs, suggesting that the solution treatment at $1130{ }^{\circ} \mathrm{C}$ was effective. However, some irregularly shaped and heterogeneously sized spots were observed in BDSS, indicating the presence of non-metallic inclusions, whereas only a few smaller spots were observed in GDSS.

EBSD inverse pole figure maps of BDSS and GDSS are shown in Figure 1C,D, respectively. It should be noted that both EBSD images have random crystallographic texture owing to the absence of any plastic deformation. Furthermore, GDSS exhibited smaller grain size in ferrite region, whereas BDSS exhibited coarse grains. The calculated grain size of ferrite for BDSS and GDSS were $1026.8 \pm 425.8 \mu \mathrm{m}$ and $906.2 \pm 297.6 \mu \mathrm{m}$, respectively. The results indicate that the grain morphologies of SDSSs are successfully modified with the addition of Gd without other phase changes. On the other hand, the grain size of austenite for both BDSS and GDSS were 178.4 $\pm 88.6 \mu \mathrm{m}$ and $183.3 \pm 107.8 \mu \mathrm{m}$ and had no significant difference between them. Generally, it is well known that growth and recovery rates of austenite are slower than those of ferrite [53]. 

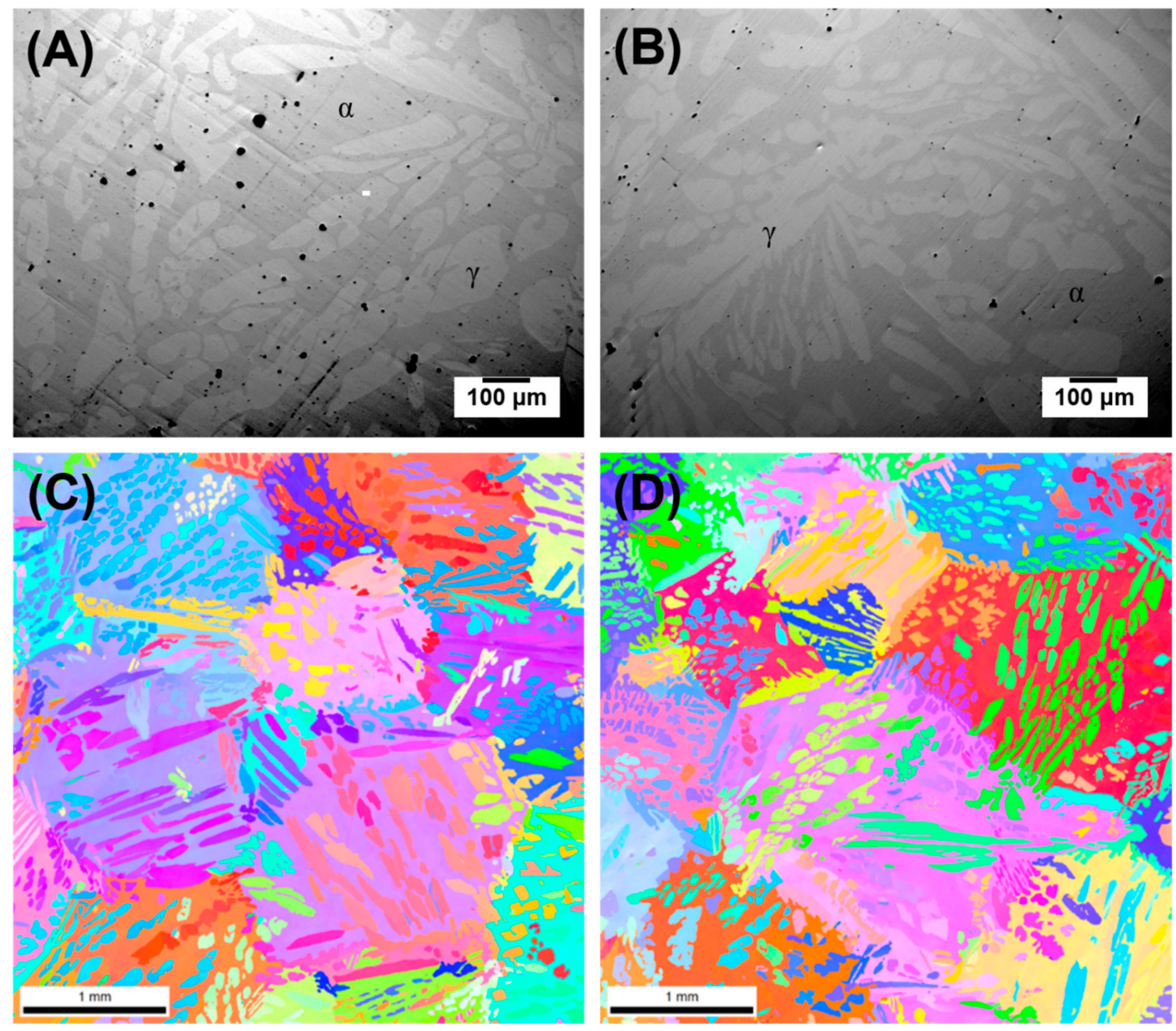

Figure 1. The microstructures of solution-treated duplex stainless steels (A) without gadolinium (BDSS) (B) with gadolinium (GDSS) and EBSD inverse pole figure maps of (C) BDSS and (D) GDSS.

The ferrite fraction and average grain size of SDSSs evaluated by EBSD mapping are shown in Figure 2. The ferrite contents in BDSS and GDSS were $57.7 \pm 3.2 \%$ and $59.3 \pm 2.4 \%$, respectively, which were the appropriate ratios for duplex stainless steels, close to the calculated values of a ferrite scope. This result demonstrated that Gd did not affect the main phase of SDSSs. Meanwhile, the average grain size of SDSSs remarkably decreased from $683.5 \mu \mathrm{m}$ to $598.3 \mu \mathrm{m}$ after adding the Gd. During casting, Gd reduced the molten SDSSs surface tension thereby decreasing the activation energy of the nuclei formation [54]. An increase in several nuclei led to a decrease in grain size, which improved the mechanical properties of SDSSs owing to the increase in the number of grain boundaries, which interrupted dislocation movement in SDSSs [16].

Figure 3 shows X-ray diffraction patterns of BDSS and GDSS after solution treatment. The main peaks in the $2 \theta$ are ranged between $40^{\circ}$ and $45^{\circ}$, corresponding to the (111) and (110) planes of austenite and ferrite, respectively. Only austenite and ferrite peaks are observed in both SDSS specimens. After solution treatment, the $\sigma$ and $\chi$ phases that affected the steels mechanical properties negatively were removed. The result is in good agreement with the optical micrograph images (Figure 1). No differences in peak intensity between BDSS and GDSS were observed, suggesting that no unexpected reactions, such as SDSS's phase transformation occurred after adding a small amount of Gd. 


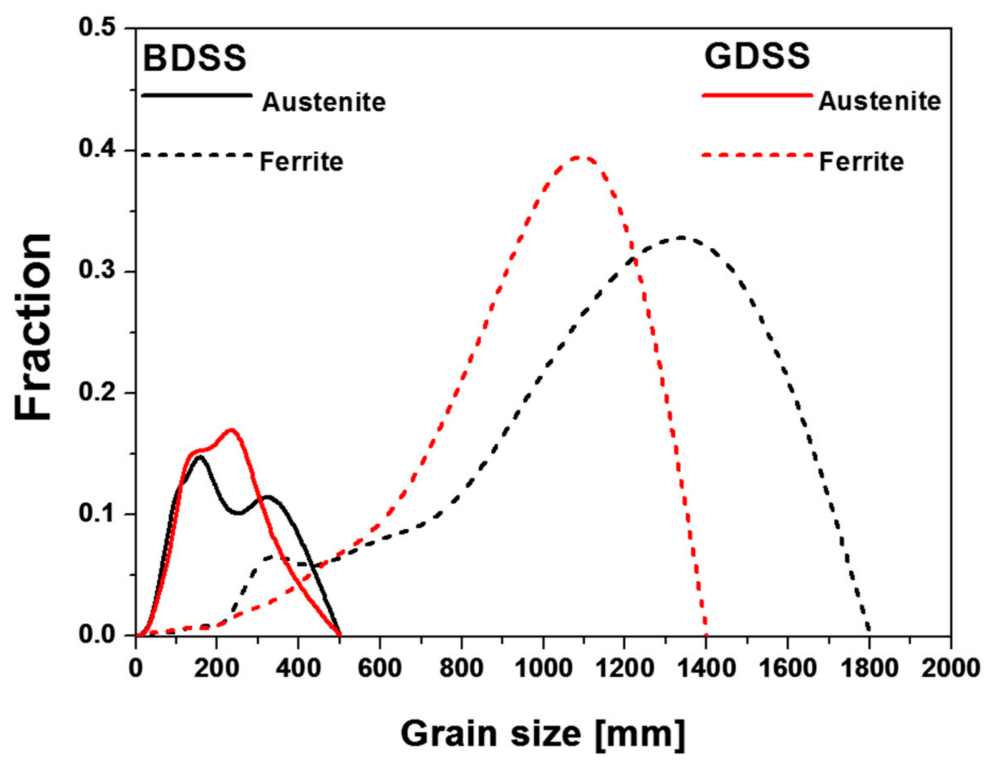

Figure 2. The grain size distributions of as-cast SDSSs for each phase characterized by electron backscatter diffraction (EBSD).

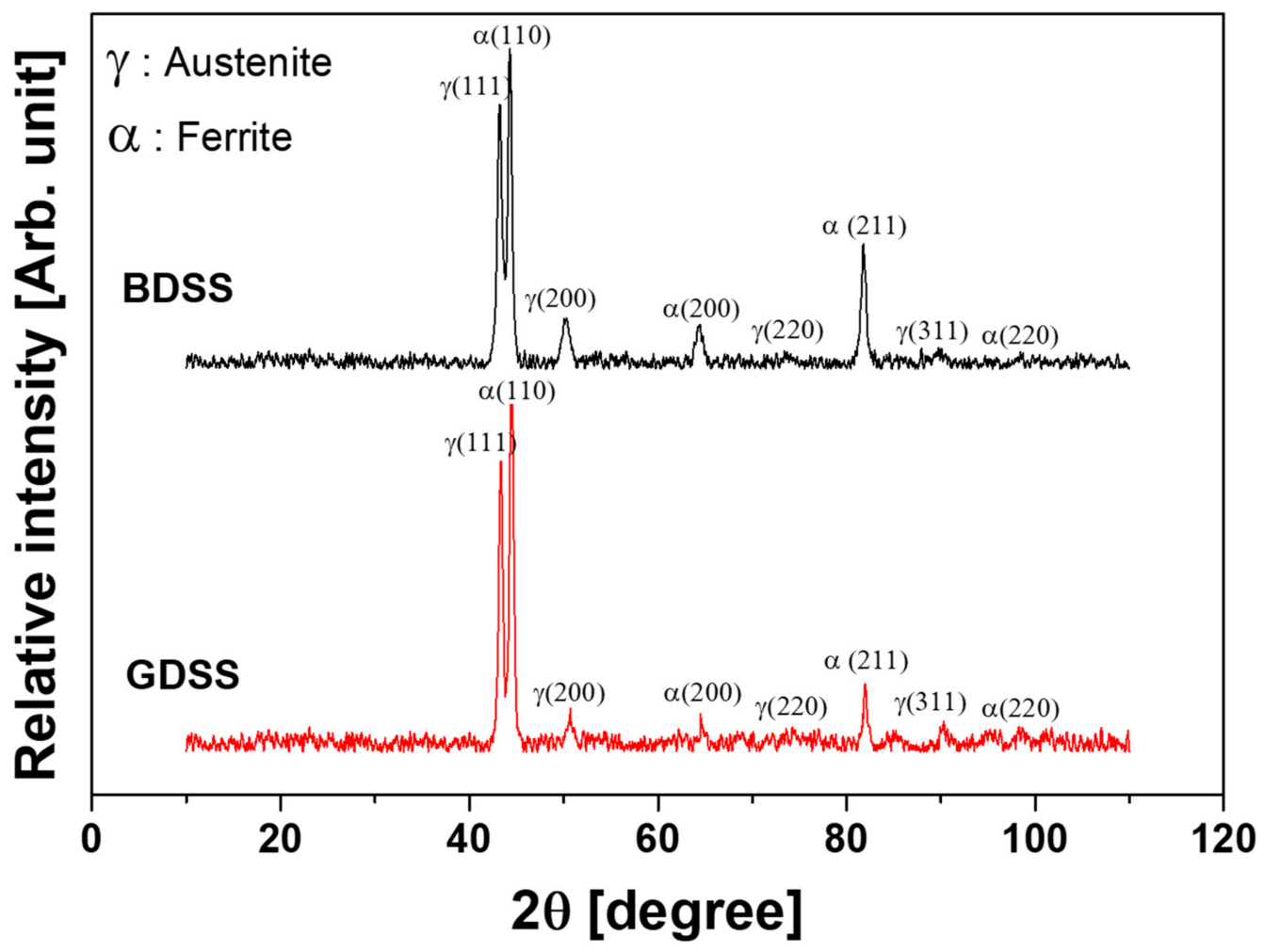

Figure 3. X-ray diffraction patterns of BDSS and GDSS.

\subsection{Characterization of Inclusions}

The microstructure changes of inclusions in SDSSs, casted with and without Gd, were further investigated by FE-SEM, as shown in Figure 4. Inclusions were detected in both ferrite and austenite phases. No clusters of inclusions were formed, and the inclusions were homogeneously distributed in both fabricated SDSSs (Figure 4A,B). Based on the BSE images polished surfaces, some irregular inclusions were found in BDSS, whereas relatively small inclusions were found in GDSS. The main 
morphology of the inclusions in BDSS was polygonal and the size of the inclusions was around $20 \mu \mathrm{m}$, as shown in the high-magnification BSE image (Figure 4C). GDSS has two types of inclusions: polygonal inclusions as observed in BDSS and smaller spherical inclusions as shown in Figure 4B. In many previous reports, it has been proven that REMs can reform the inclusion shapes from angulated to non-angulated or spherical shapes with the ability to enhance the mechanical properties of metal alloys, such as the impact toughness [10]. The non-angulated inclusions in GDSS comprised of dark and light regions (Figure 4D). This type of inclusion was observed in steels modified by REM additives. These results suggest that the non-metallic inclusions detected in GDSS originate from the deoxidation reactions upon the addition of Gd [55].
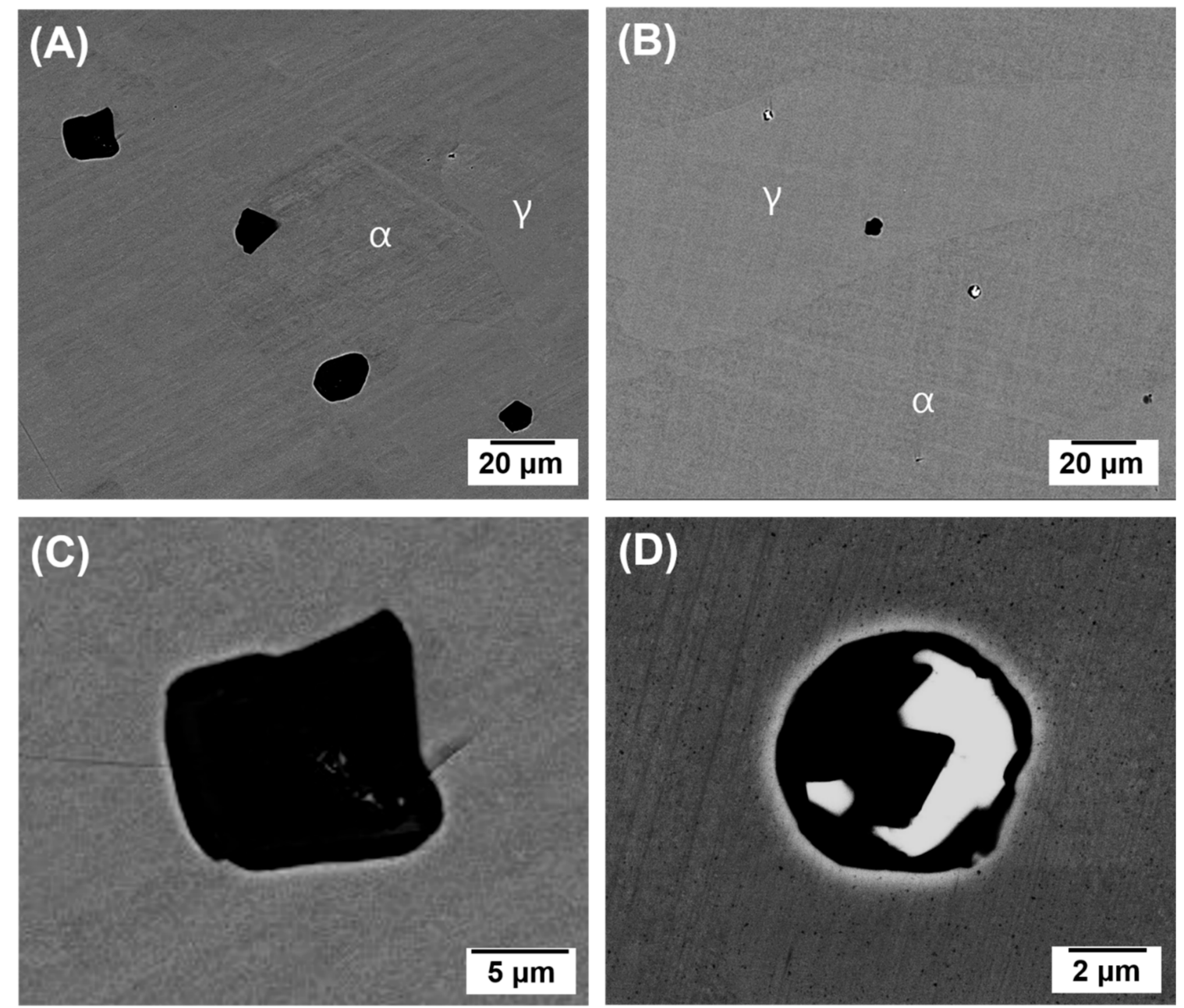

Figure 4. Backscattered electron micrographs of (A,C) BDSS and (B,D) GDSS. (A,B) were taken at low magnification and $(\mathbf{C}, \mathbf{D})$ at high magnification.

The EDS was also used to quantify the inclusions' chemical compositions, and the representative inclusions observed in both BDSS and GDSS (Figure 4C,D) were analyzed, as shown in Table 2. The observed elements contained in the inclusions in BDSS were $\mathrm{O}, \mathrm{Cr}$ and $\mathrm{Mn}$ and their weight fractions were $21.8 \%, 50.9 \%$, and $27.3 \%$, respectively. Based on the EDS results, the polygonal inclusions in BDSS consist of $\mathrm{Cr}_{2} \mathrm{O}_{3}$ and $\mathrm{MnO}$ inclusions, which represent non-metallic inclusions formed in steels during casting [56,57]. The EDS analysis of inclusions in GDSS was performed for both the light regions and dark regions. $\mathrm{Gd}, \mathrm{Si}$, and $\mathrm{Fe}$, as well as $\mathrm{O}, \mathrm{Cr}$, and $\mathrm{Mn}$, which were the components of the inclusions in BDSS, were the main elements of the inclusions in GDSS. The EDS analysis results reveal that Gd-based oxides are the core of the complex inclusions, and (Mn, $\mathrm{Cr}, \mathrm{Si}$ )-based oxides surround 
the Gd-based oxides, such as $\mathrm{Gd}_{2} \mathrm{O}_{3}$. Thus, the addition of Gd to SDSS resulted in the transformation of the non-metallic inclusions in SDSS, as well as the size grains reduction. Moreover, the addition of a small amount of $\mathrm{Gd}$ with an undisclosed SDSS deoxidizing capacity resulted in a substantial change in the oxide content. Thermodynamically, REM-based oxides or oxysulfides are stable compounds owing to their formation of low standard free energies [58]. The standard Gibbs free energy formation for $\mathrm{Gd}_{2} \mathrm{O}_{3}$ is $-2457 \mathrm{~kJ} / \mathrm{mol}$ is larger than those for $\mathrm{MnO}, \mathrm{Cr}_{2} \mathrm{O}_{3}$, and $\mathrm{SiO}_{2}$. Therefore, it is expected that Gd-based oxides were formed in the melting state, followed by reaction of the remaining $\mathrm{O}$ with the molten SDSS and other elements, such as Si, Mn, and Cr.

Table 2. Quantitative chemical composition of the inclusions in each BDSS characterized by EDS (wt. \%).

\begin{tabular}{ccccccc}
\hline Specimen & $\mathbf{O}$ & $\mathbf{C r}$ & $\mathbf{M n}$ & $\mathbf{F e}$ & $\mathbf{S i}$ & $\mathbf{G d}$ \\
\hline BDSS & 21.8 & 50.9 & 27.3 & - & - & - \\
GDSS (light) & 15.0 & 10.1 & 9.9 & 7.3 & 10.1 & 47.6 \\
GDSS (dark) & 19.2 & 41.1 & 23.6 & 12.4 & 3.7 & - \\
\hline
\end{tabular}

Figure 5 presents the inclusion size distributions of the as-cast SDSSs and the average area of the inclusions, as well as the average distance between the inclusions in BDSS and GDSS. As depicted in Figure 5A, the inclusion size distribution shifts slightly to the left, indicating a decrease in inclusion size upon the addition of Gd. GDSS showed a bell-shaped curve, similar to a normal distribution centered at $6 \mu \mathrm{m}$, whereas BDSS had various sizes of inclusions with coarse inclusions over $20 \mu \mathrm{m}$. Approximately $85.2 \%$ and $92.9 \%$ of the inclusion sizes were between 0 and $11 \mu \mathrm{m}$ in BDSS and GDSS, respectively. The calculated average size of the inclusions in GDSS was about $5.70 \mu \mathrm{m}$, which was an $18.7 \%$ reduction compared with the inclusions in BDSS (approximately $7.01 \mu \mathrm{m}$ ). This result demonstrated that the addition of Gd to SDSS significantly reduced the number of coarse inclusions and the average inclusion size.
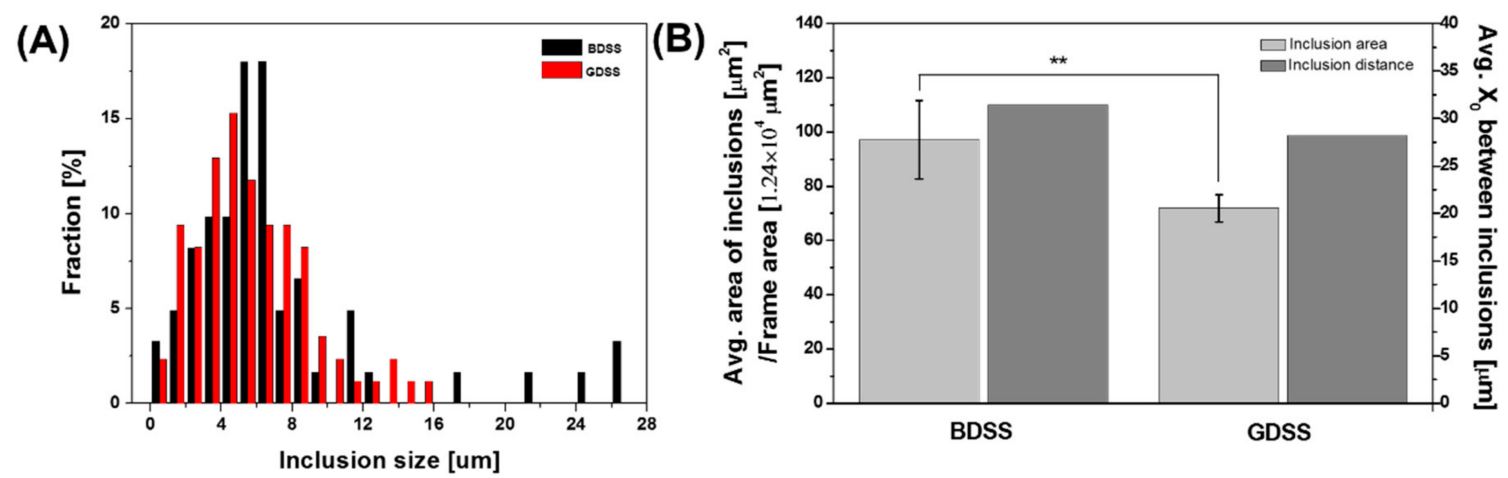

Figure 5. (A) Inclusion size distributions of as-cast SDSSs. (B) the average area of inclusions and the average distance between inclusions in BDSS and GDSS $(* * p<0.005)$.

The area of the inclusions per frame in GDSS significantly decreased compared with the area of the inclusions in BDSS, as shown in Figure 5B $(p<0.005)$. The decrease in the total area of inclusions was attributed to a decrease in the total $\mathrm{O}$ content with the addition of $\mathrm{Gd}$. This result was consistent with the results observed in the optical image of BDSS, comprising of many heterogeneous inclusions (Figure 1A).

Rice et al. investigated the effects of inclusion fraction and the spacing between the inclusions on the ductile fracture behavior [59]. They developed a model called the Rice and Johnson model. In their model, the average nearest-neighbor spacing within the inclusions $\left(X_{0}\right)$ is calculated with the equation given in Section 2 [59]. In this study, the distances between the inclusions in both BDSS and GDSS were quantified by calculating the sizes and fractions of the inclusions. As Gd was added to 
SDSS, the average distance of the inclusions marginally decreased from $31.4 \mu \mathrm{m}$ to $28.2 \mu \mathrm{m}$. With a simultaneous decrease in the inclusion size and fraction, the distances between inclusions were similar. The number of inclusions per unit area $\left(N_{A}\right)$ is directly proportional to the fraction of inclusions and inversely proportional to the area of each inclusion:

$$
N_{A} \propto \frac{f}{R_{0}^{2}}
$$

From this equation, the number of inclusions per unit area in GDSS is larger than that of BDSS by about $11 \%$. It should be noted a greater number of smaller inclusions were distributed in GDSS compared with BDSS.

\subsection{Charpy Impact Tests of SDSSs}

The influence of the inclusion structure and properties with the addition of $\mathrm{Gd}$ on impact toughness was investigated using Charpy impact energy tests. Figure 6A,B show the fracture specimens after Charpy V-notch tests at various temperatures from $-196{ }^{\circ} \mathrm{C}$ to $200{ }^{\circ} \mathrm{C}$ for BDSS and GDSS, respectively. As the experimental temperature decreased from $200{ }^{\circ} \mathrm{C}$ to $-196{ }^{\circ} \mathrm{C}$, the fracture surfaces of BDSS had a mirror-like shiny appearance (Figure 6A). Moreover, the surfaces of the specimens at lower temperatures were flat and the original shape was maintained, whereas the surfaces of the specimens at higher temperatures seemed to be bumpy with irregular shapes. The fracture surfaces exhibited both shiny regions and dull regions, corresponding to brittle and ductile fracture, respectively. These results suggested that a ductile-to-brittle transition occurred because of a change in experimental temperature. The GDSS fracture surfaces at various temperatures were similar to those of BDSS, as shown in Figure 6B. However, the fracture surface of GDSS at $0{ }^{\circ} \mathrm{C}$ seemed to be completely rough, whereas that of BDSS at $0^{\circ} \mathrm{C}$ still had some shiny regions, indicating that the GDSS fracture mode changed at a lower temperature.

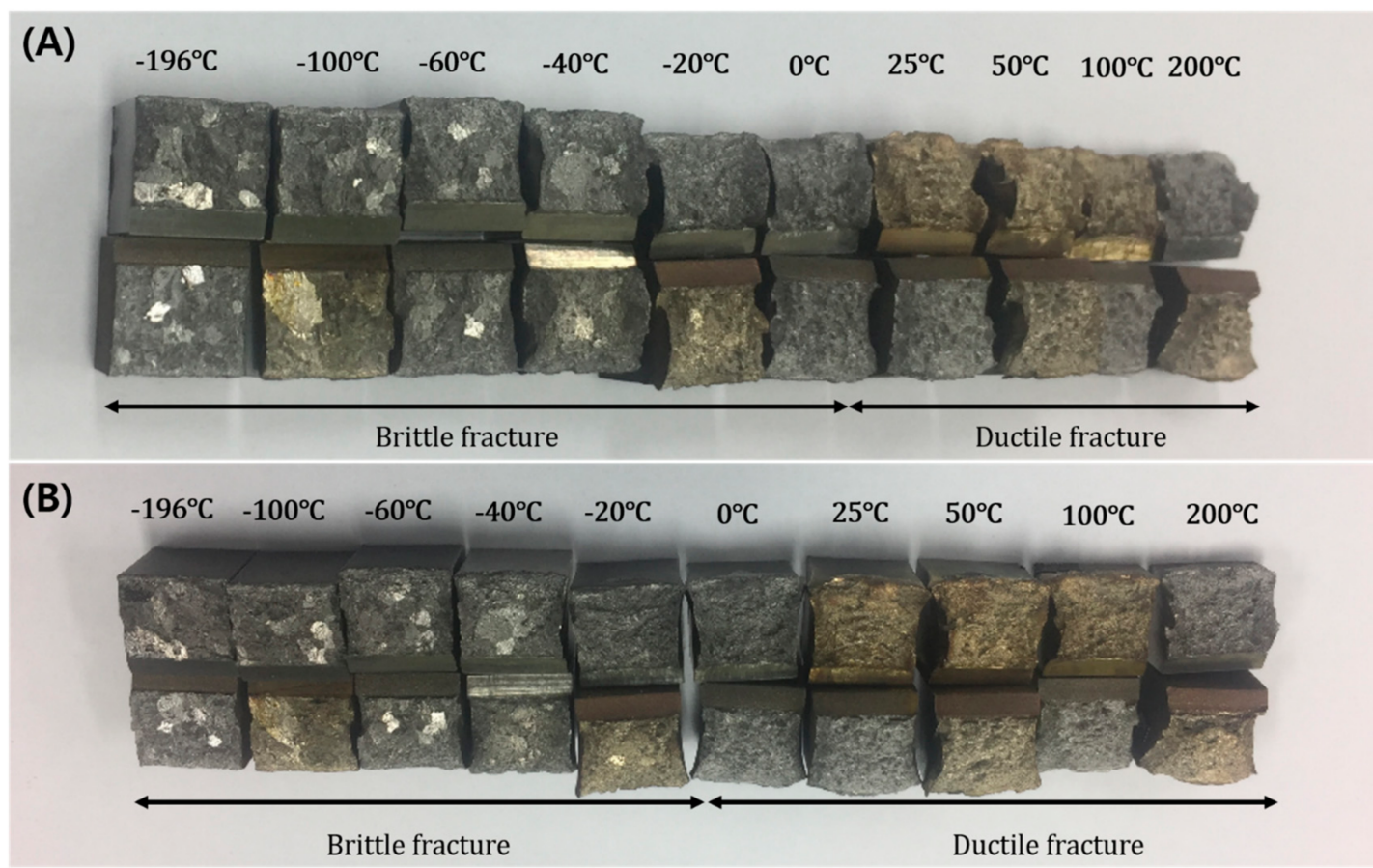

Figure 6. Fracture specimens after Charpy V-notch tests at various temperatures from $-196{ }^{\circ} \mathrm{C}$ to $200{ }^{\circ} \mathrm{C}$ for (A) BDSS and (B) GDSS. 
Figure 7 shows the BDSS and GDSS Charpy impact energies from $-196^{\circ} \mathrm{C}$ to $200{ }^{\circ} \mathrm{C}$. The Charpy impact tests were performed at ten different temperatures $\left(-196{ }^{\circ} \mathrm{C},-100{ }^{\circ} \mathrm{C},-60^{\circ} \mathrm{C},-40{ }^{\circ} \mathrm{C},-20^{\circ} \mathrm{C}\right.$, $0{ }^{\circ} \mathrm{C}, 25^{\circ} \mathrm{C}, 60^{\circ} \mathrm{C}, 100{ }^{\circ} \mathrm{C}$, and $200^{\circ} \mathrm{C}$ ) to construct a sufficiently detailed absorbed energy curve that could be used to calculate various impact transition temperatures, as well as the ductile-to-brittle transition temperature (DBTT). The SDSSs impact energies as a function of experimental temperature can be expressed by a hyperbolic tangent function proposed by Oldfield as follows [60]:

$$
\text { Charpy impact energy }=A+B \tan \mathrm{h} \frac{T-T_{0}}{C}
$$

where $T$ is the experimental temperature, $\mathrm{T} 0$ is the mid-transition temperature, and $\mathrm{C}$ is the slope of at $T_{0}$. Moreover, $A+B$ and $A-B$ are the upper shelf energy (USE) and lower shelf energy (LSE), respectively [60]. The constants $A, B, C$, and $T_{0}$ in this equation were calculated for both BDSS and GDSS, as shown in Table 3. Generally, specimens in the low temperature region have limited movement of domain walls and dislocations, whereas thermal activation permits more movement of domain walls and dislocations, resulting an increase in impact energy [61]. Charpy impact energy values for GDSS were larger than those of BDSS at all the experimental temperatures. The GDSS measured of LSE and USE were $8.0 \mathrm{~J}$ and $169.8 \mathrm{~J}$, and those of BDSS were $6.0 \mathrm{~J}$ and $156.0 \mathrm{~J}$, respectively. The theoretical LSE and USE for both SDSSs calculated from constants $A$ and $B$ were similar to the measured values, indicating that the obtained Charpy impact energy transition curves of both SDSSs were well-fitted by typical transition curves. In other words, three distinctive regions, namely lower shelf region, transition region, and upper shelf region, were observed. The mid-transition temperature shifted from $-32.3^{\circ} \mathrm{C}$ to $-37.9^{\circ} \mathrm{C}$ by the addition of $\mathrm{Gd}$, corresponding to a decrease in DBTT by approximately $6{ }^{\circ} \mathrm{C}$.

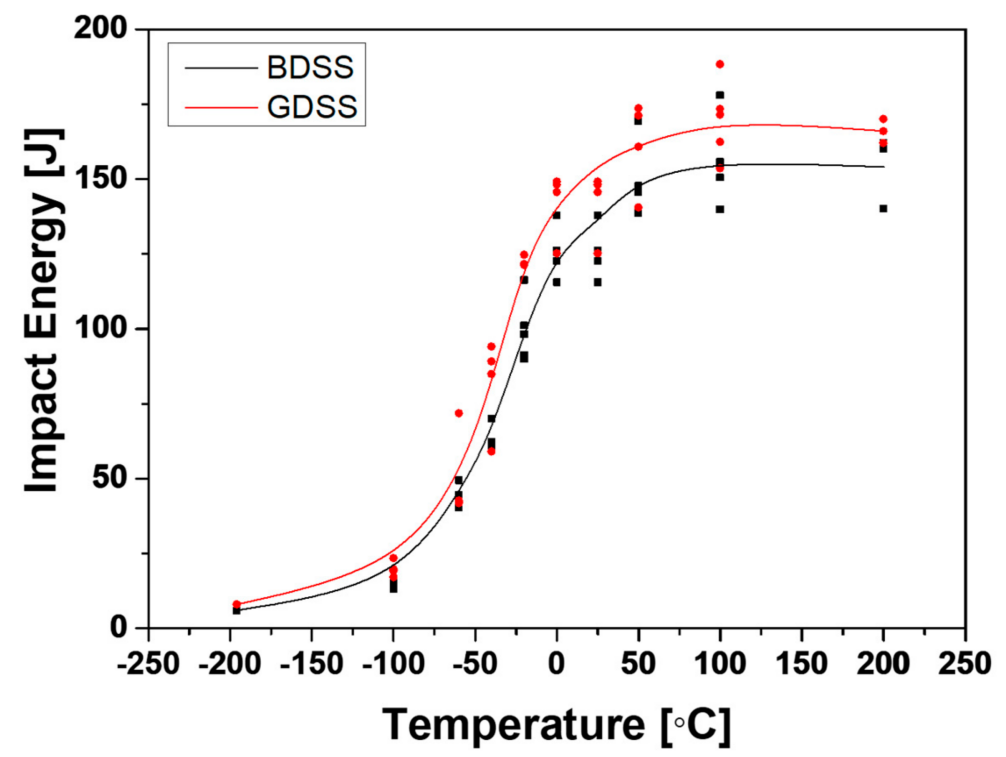

Figure 7. Fracture Charpy impact energies of BDSS and GDSS as a function of temperature from $-196^{\circ} \mathrm{C}$ to $200^{\circ} \mathrm{C}$.

Table 3. Impact of energy transition curve parameters and absorbed energy obtained from Charpy impact tests from the fabricated SDSSs.

\begin{tabular}{ccccccc}
\hline \multirow{2}{*}{ Specimen } & \multirow{A}{*}{} & \multirow{2}{*}{} & $\boldsymbol{T}_{\mathbf{0}}$ & $\boldsymbol{C}$ & \multicolumn{2}{c}{ Absorbed Energy (J) } \\
\cline { 6 - 8 } & & & & & LSE & USE \\
\hline BDSS & 80.2 & 74.6 & -32.3 & 50.4 & 6.0 & 156.0 \\
GDSS & 87.6 & 78.6 & -37.9 & 43.5 & 8.0 & 169.8 \\
\hline
\end{tabular}


The FE-SEM was used to examine the fracture surfaces of both SDSSs after the Charpy impact tests and the results were presented in Figure 8. The fracture surfaces of both BDSS and GDSS in the upper shelf region exhibited ductile fracture, as indicated by a variety of dimples (Figure 8E,J). Whereas cleavage with torn ridges indicating brittle fracture was observed in the lower shelf region (Figure 8A,F). However, a small increase in Charpy impact energy at cryogenic temperatures occurred upon the addition of $\mathrm{Gd}$, whereas a larger difference between the Charpy impact energies was observed at high temperature as shown in Figure 7. At temperatures near the mid-transition temperature, the fracture modes for both SDSSs comprised both dimple and quasi-cleavage modes (Figure 8B-D,G-I).
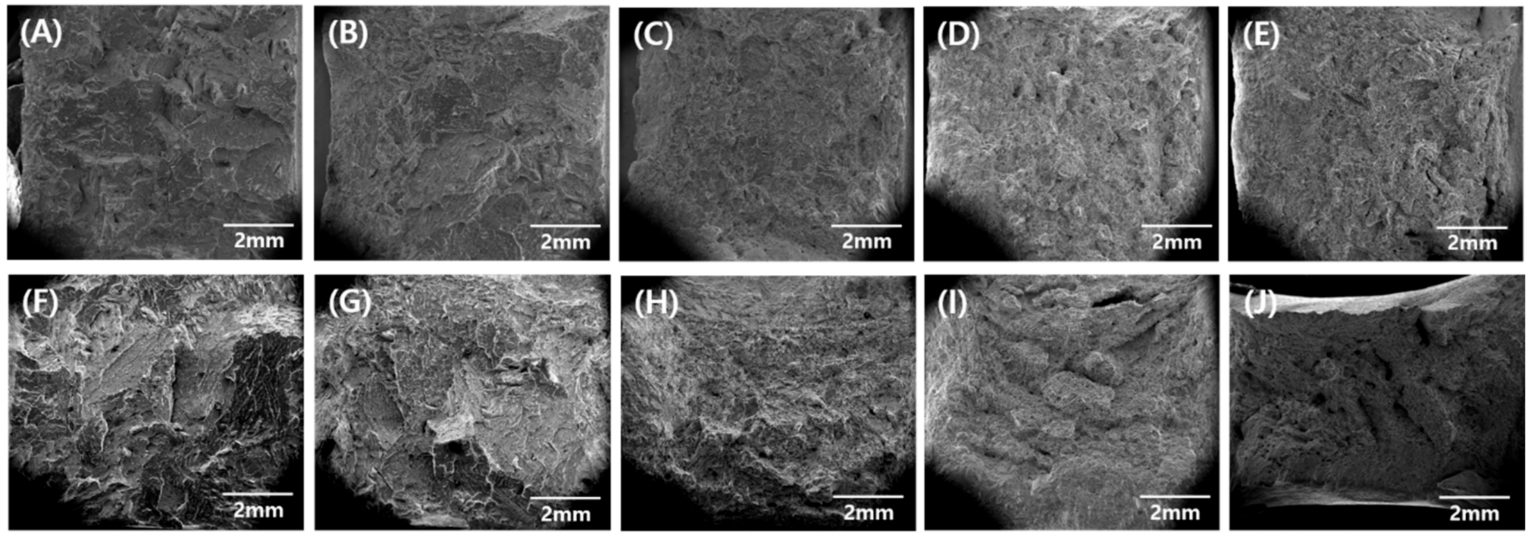

Figure 8. Low-magnification FE-SEM images of fractured surfaces of BDSS (A-E) and GDSS (F-J) after Charpy impact tests at $(\mathbf{A}, \mathbf{F})-196^{\circ} \mathrm{C},(\mathbf{B}, \mathbf{G})-60{ }^{\circ} \mathrm{C},(\mathbf{C}, \mathbf{H})-20^{\circ} \mathrm{C},(\mathbf{D}, \mathbf{I}) 50^{\circ} \mathrm{C}$, and $(\mathbf{E}, \mathbf{J}) 200{ }^{\circ} \mathrm{C}$.

Figure 9 shows high-magnification FE-SEM images of the fracture surfaces for both SDSSs at temperatures of $-60{ }^{\circ} \mathrm{C},-20^{\circ} \mathrm{C}$, and $50{ }^{\circ} \mathrm{C}$ analyzed to study the change in fracture mode in the transition region. The fracture surface of BDSS at $-60{ }^{\circ} \mathrm{C}$ exhibited a cleavage-dominated fracture behavior with complex river patterns (Figure 9A). However, the fracture surface of GDSS at $-60{ }^{\circ} \mathrm{C}$, which had a $10 \%$ higher absorbed energy than BDSS, showed a greater proportion of various sizes of dimples and cleavage facets (Figure 9D). At $-20^{\circ} \mathrm{C}$, the absorbed energy of BDSS increased by over 20\% relative to that of GDSS and the absorbed energy values for BDSS and GDSS were $99.4 \mathrm{~J}$ and $122.5 \mathrm{~J}$, respectively. The fraction of quasi-cleavage facets with small cleavage steps was approximately two thirds in BDSS (Figure 9B), and the ductile fracture areas covered approximately half of the whole fracture surface in GDSS (Figure 9E). On the other hand, at $50{ }^{\circ} \mathrm{C}$, many dimples arising from ductile fracture appeared in both BDSS and GDSS (Figure 9C,F). However, most of the dimples in GDSS were bigger and deeper than those in BDSS. In general, the larger and deeper the dimple, the better plastic properties $[62,63]$. These results are in accordance with a previous report that reveals the relationship between dimple structure and mechanical properties of steels [64]. Das et al. confirmed that the ductility value of a copper-strengthened high-strength low-alloy (HSLA) was directly proportional to the diameter of dimples.

In Table 4, various impact transition temperatures (ITT) calculated from Charpy impact tests are listed. According to BS 7910:1999, ASTM E185-82, 27J-ITT and 68J-ITT are generally used to evaluate the Charpy impact transition behavior of ferritic steels and nuclear reactor steels [47,48]. The temperatures at which the Charpy impact energy was $27 \mathrm{~J}$ (27J-ITT) for BDSS and GDSS were estimated at $-77.3^{\circ} \mathrm{C}$ and $-82.4{ }^{\circ} \mathrm{C}$, respectively allowed fitting of the data with the hyperbolic tangent function. When the impact toughness is $68 \mathrm{~J}$ (68J-ITT) for BDSS and GDSS, the temperature was $-40.6{ }^{\circ} \mathrm{C}$ and $-49.0^{\circ} \mathrm{C}$, respectively, around $35^{\circ} \mathrm{C}$ higher than 27J-ITT. Remarkably, both 27J-ITT and 68J-ITT values decreased by $5-8{ }^{\circ} \mathrm{C}$ upon the addition of $\mathrm{Gd}$, suggesting that the Charpy impact property was significantly affected by $\mathrm{Gd}$ addition. 

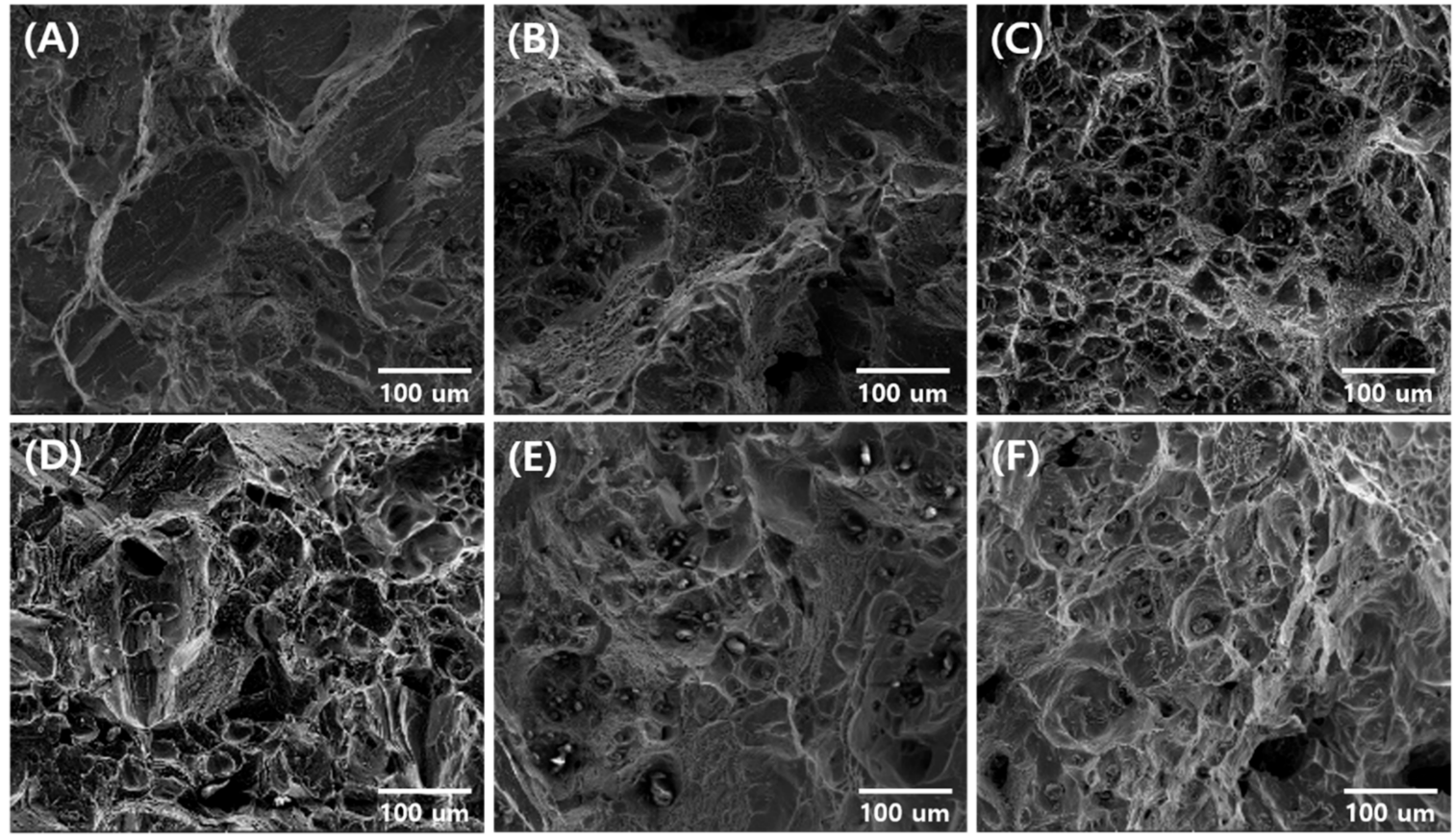

Figure 9. High-magnification FE-SEM images fracture surfaces of BDSS (A-C) and GDSS (D-F) after Charpy impact tests at $(\mathbf{A}, \mathbf{D})-60^{\circ} \mathrm{C},(\mathbf{B}, \mathbf{E})-20{ }^{\circ} \mathrm{C}$, and $(\mathbf{C}, \mathbf{F}) 50{ }^{\circ} \mathrm{C}$.

Table 4. Impact transition temperatures calculated from Charpy impact tests on the SDSSs.

\begin{tabular}{ccccc}
\hline \multirow{2}{*}{ Specimen } & \multicolumn{4}{c}{ Impact Transition Temperature $\left({ }^{\circ} \mathrm{C}\right)$} \\
\cline { 2 - 5 } & 27J-ITT & 68J-ITT & DBTT-ETT & DBTT-FATT \\
\hline BDSS & -77.3 & -40.6 & -31.8 & 0.1 \\
GDSS & -82.4 & -49.0 & -38.2 & -22.4 \\
\hline
\end{tabular}

By determining the DBTTs average value of LSE and USE (DBTT-ETT), the temperature was $-31.8^{\circ} \mathrm{C}$ and $-38.2{ }^{\circ} \mathrm{C}$ for BDSS and GDSS, respectively, and these values were quite similar to the mid-transition temperatures (Table 3). Therefore, significant improvements in Charpy impact properties (with USE of $169.8 \mathrm{~J}$, 68J-ITT of $-49{ }^{\circ} \mathrm{C}$, and DBTT-ETT of $-38.2{ }^{\circ} \mathrm{C}$ ) were achieved by modifying the microstructure of SDSS with a very small input of $\mathrm{Gd}$. The mechanism is explained as follows: First, Gd acts as a grain refiner, reducing the DBTT and increasing the USE. Second, the size and fraction of non-metallic inclusions are decreased by the reduction of O in SDSS with Gd acting as a deoxidizer. Although the number of inclusions increases and the average distance between inclusions decreases, the advantages of Gd addition make the modified SDSS a potential structural metal that can function under the extreme conditions. Moreover, the change in the shape of inclusions as globular shape might result in better impact toughness.

The DBTT can be evaluated with five methods: the energy transition temperature (ETT) which is considered to be the average value of LSE and USE, lateral expansion, shear fracture appearance, load diagram, and master curve [65-68]. In this study, an additional method based on fracture appearance transition temperature (FATT) was used. Figure 10 shows the average fraction of dimples obtained from surface fracture analysis for BDSS and GDSS. The curves fitted to the experimental data was appropriately adjusted with the Charpy impact energy curves expressed by a hyperbolic tangent function, as shown in Figure 7. The DBTT-FATTs that indicated 50:50 ductile behavior from the fractured surface of the specimens were $0.1^{\circ} \mathrm{C}$ and $-22.4{ }^{\circ} \mathrm{C}$ for BDSS and GDSS, respectively (Table 4). The DBTT value for BDSS, obtained from the FATT method, was almost $32{ }^{\circ} \mathrm{C}$ higher than that of the ETT method. Furthermore, the difference in the DBTT-FATT value between BDSS and GDSS was 
greater than in the other ITT values, which included the DBTT-ETT. Some researchers have also found differences in the DBTT-ETT and DBTT-FATT values [69-71], suggesting that they could occur when the shape of the transition curve was unusual with an ambiguous transition point or at significantly low USE value [71]. By using a symmetric hyperbolic tangent function, as used for the Charpy impact energy fitting curves, the slope (C) of the transition region of BDSS had a larger standard error and a lower coefficient of determination, R-squared than that of GDSS.

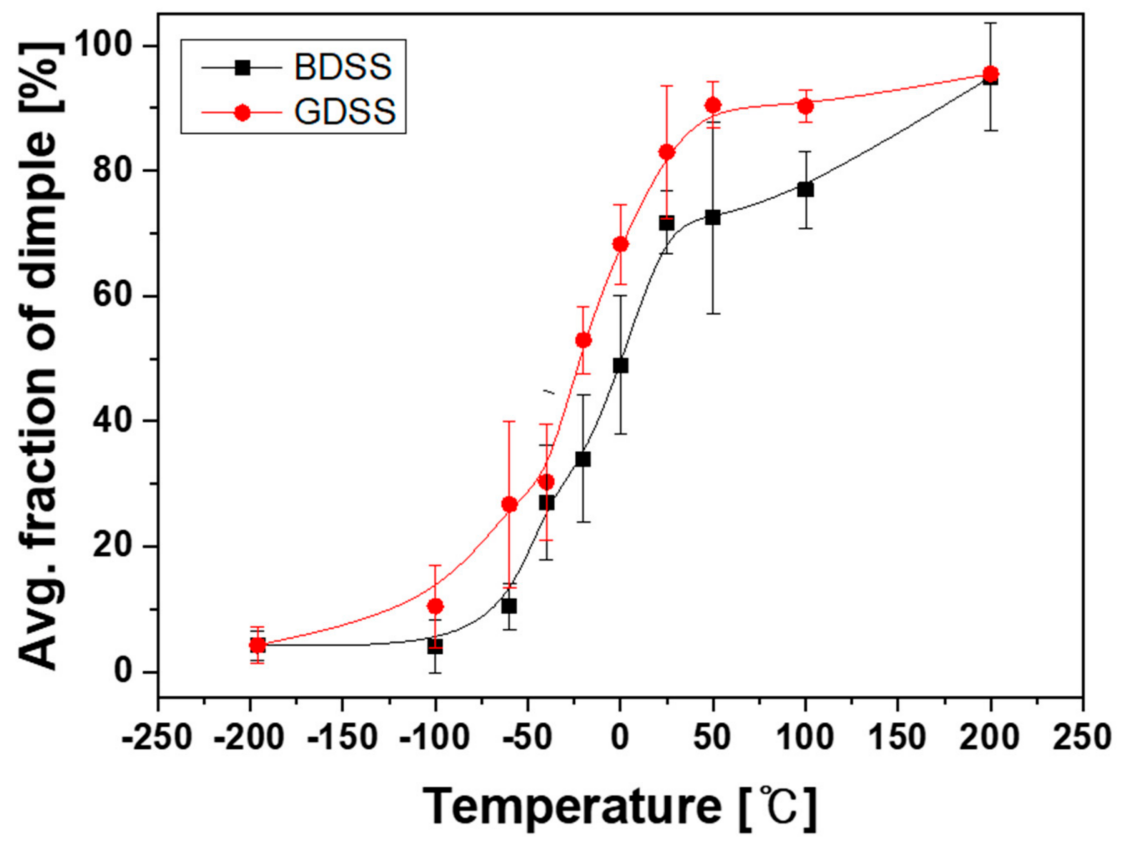

Figure 10. The average fraction of ductile fracture obtained from fracture surfaces of BDSS and GDSS at various temperatures.

Microstructure and chemical composition of typical inclusions in each BDSS and GDSS are shown in Figure 11. The inclusions in dimples are clearly visible after Charpy impact test. The shape of inclusion was certainly different in both SDSSs. In the dimple of BDSS, the inclusions were angulated (Cr, Mn)-based oxides (Figure 11A,C), whereas relatively spherical shaped ( $\mathrm{Gd}, \mathrm{Cr}, \mathrm{Si}$ )-based oxides were found in the dimple of GDSS (Figure 11B,D). During casting process, Gd acted as a flux and hence formed floating slags with large inclusions [10]. Gd also decreased the size of inclusions and changed the inclusions to be more spherical in shape, thus further improved the Charpy toughness of SDSS. 

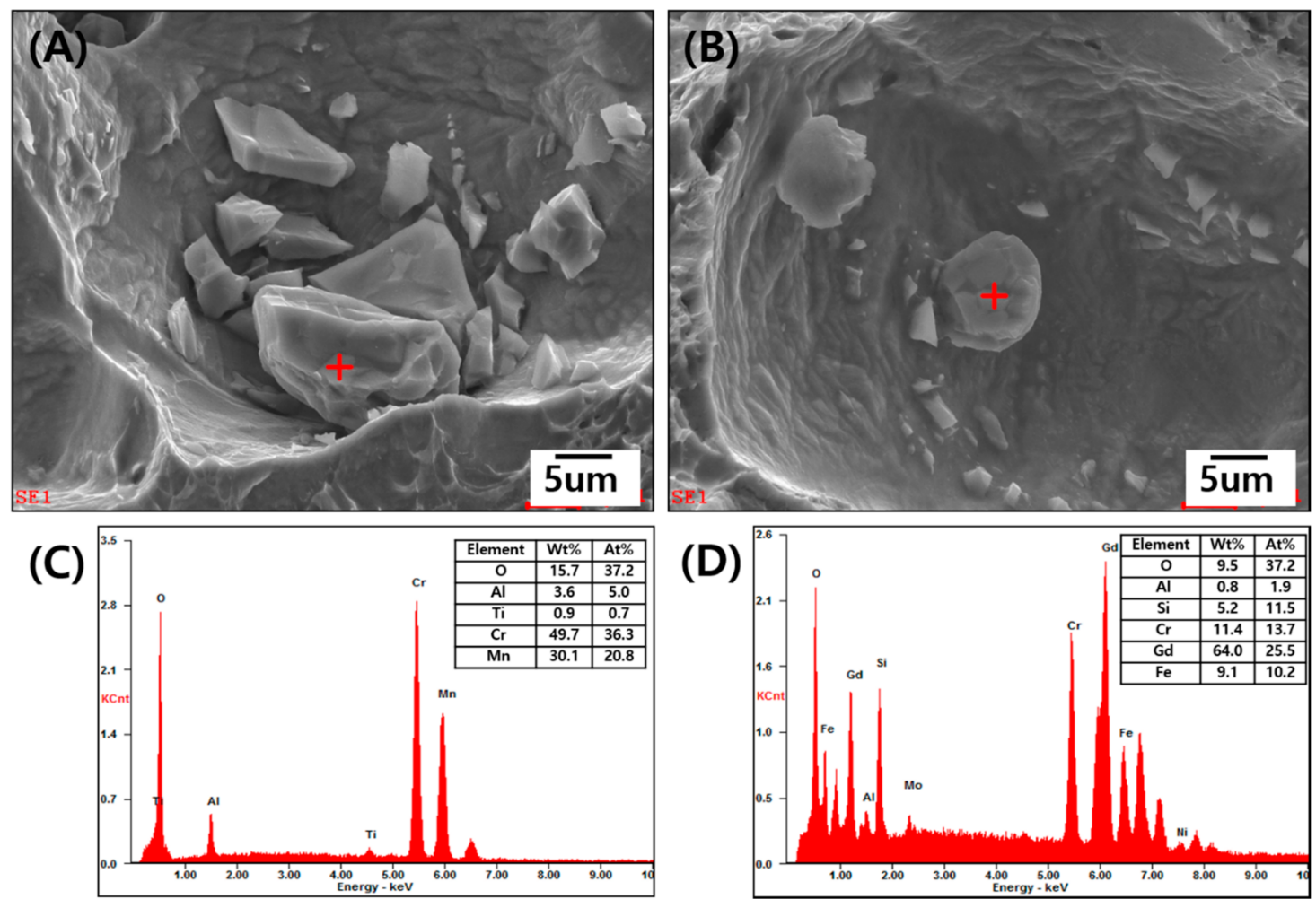

Figure 11. (A,B) FE-SEM micrographs and (C,D) EDS spectra of inclusions in $(\mathbf{A}, \mathbf{C})$ BDSS and (B,D) GDSS dimples after Charpy impact tests at $25^{\circ} \mathrm{C}$.

\section{Conclusions}

In this study, the effect of Gd addition on the microstructures and Charpy impact properties of super duplex stainless steels was investigated. A890 grade 7A SDSSs with and without Gd were successfully fabricated by an air-casting method. Reduction of the grain size and inclusion of SDSS were achieved by Gd addition because of a decrease in the nuclei formation's activation energy and high reactivity of Gd with $\mathrm{O}$. The addition of Gd to SDSS also resulted in the transformation of the non-metallic inclusions, and a reduction of their average fraction of inclusions. These combined effects improved the impact toughness and ductility of SDSS even though the relative number of inclusions increased and the average distance between them decreased. Compared with BDSS, GDSS demonstrated a higher absorbed energy, including LSE and USE, as well as a lower impact transition temperature (27J-ITT, 68J-ITT, and DBTT). Specifically, the DBTT calculated by FATT significantly decreased by more than $20^{\circ} \mathrm{C}$ upon the addition of $\mathrm{Gd}$. This approach to improve microstructure and mechanical property of SDSS was effectively performed. Therefore, the modified SDSS by the addition of $\mathrm{Gd}$ have a great potential to become a structural alloy for applications under some extreme conditions.

Author Contributions: S.-W.L., M.-J.K., S.-R.J. and Y.-J.K. conducted the experimental and analytical works. B.-M.M. and H.-D.J. designed, supervised the project, and wrote the manuscript. All the authors contributed to the critical reading and editing of the final version of the manuscript.

Funding: This work was supported by the Nuclear Power Core Technology Development Program of the Korea Institute of Energy Technology Evaluation and Planning (KETEP) (Grant no. 20141710201690) and the National Research Foundation of Korea (NRF) grant funded by the Korea government (MSIT) (No. 2017R1C1B2012459 and No. 2018R1C1B6001003).

Acknowledgments: This work described in this paper was supported by a grant from Korea Institute of Industrial Technology.

Conflicts of Interest: The authors declare no conflict of interest. 


\section{References}

1. Naumov, A. Review of the world market of rare-earth metals. Russ. J. Non-Ferr. Met. 2008, 49, 14-22.

2. Shinjoh, H. Rare earth metals for automotive exhaust catalysts. J. Alloys Compd. 2006, 408, 1061-1064. [CrossRef]

3. Shuang, L.; Xiaodong, W.; Duan, W.; Rui, R. Ceria-based catalysts for soot oxidation: A review. J. Rare Earths 2015, 33, 567-590.

4. Ronda, C.; Jüstel, T.; Nikol, H. Rare earth phosphors: Fundamentals and applications. J. Alloys Compd. 1998, 275, 669-676. [CrossRef]

5. Zhu, H.; Lin, C.C.; Luo, W.; Shu, S.; Liu, Z.; Liu, Y.; Kong, J.; Ma, E.; Cao, Y.; Liu, R.-S. Highly efficient non-rare-earth red emitting phosphor for warm white light-emitting diodes. Nat. Commun. 2014, 5, 4312. [CrossRef] [PubMed]

6. Liu, G. Advances in the theoretical understanding of photon upconversion in rare-earth activated nanophosphors. Chem. Soc. Rev. 2015, 44, 1635-1652. [CrossRef] [PubMed]

7. Khare, A.; Mishra, S.; Kshatri, D.; Tiwari, S. Optical properties of rare earth doped srs phosphor: A review. J. Electron. Mater. 2017, 46, 687-708. [CrossRef]

8. Liu, C.; Revilla, R.I.; Liu, Z.; Zhang, D.; Li, X.; Terryn, H. Effect of inclusions modified by rare earth elements (Ce, La) on localized marine corrosion in Q460NH weathering steel. Corros. Sci. 2017, 129, 82-90. [CrossRef]

9. Gao, J.; Fu, P.; Liu, H.; Li, D. Effects of rare earth on the microstructure and impact toughness of H13 steel. Metals 2015, 5, 383-394. [CrossRef]

10. Ahn, J.-H.; Jung, H.-D.; Im, J.-H.; Jung, K.H.; Moon, B.-M. Influence of the addition of gadolinium on the microstructure and mechanical properties of duplex stainless steel. Mater. Sci. Eng. A 2016, 658, 255-262. [CrossRef]

11. Li, H.-Z.; Liu, H.-T.; Liu, Z.-Y.; Wang, G.-D. Microstructure, texture evolution and magnetic properties of strip-casting non-oriented 6.5 wt. \% Si electrical steel doped with cerium. Mater. Charact. 2015, 103, 101-106. [CrossRef]

12. Yu, X.; Zhang, Z.; Xie, J. Effects of rare earth elements doping on ordered structures and ductility improvement of Fe-6.5 wt\% Si alloy. Mater. Lett. 2016, 184, 294-297. [CrossRef]

13. Lim, H.K.; Byun, S.H.; Lee, J.Y.; Lee, J.W.; Kim, S.M.; Lee, S.M.; Kim, H.E.; Lee, J.H. Radiological, histological, and hematological evaluation of hydroxyapatite-coated resorbable magnesium alloy screws placed in rabbit tibia. J. Biomed. Mater. Res. B 2017, 105, 1636-1644. [CrossRef] [PubMed]

14. Riposan, I.; Chisamera, M.; Uta, V.; Stan, S.; Naro, R.; Williams, D. The importance of rare earth contribution from nodulizing alloys and their subsequent effect on the inoculation of ductile iron. Int. J. Met. 2014, 8, 65-80. [CrossRef]

15. Ha, H.; Park, C.; Kwon, H. Effects of misch metal on the formation of non-metallic inclusions and the associated resistance to pitting corrosion in 25\% Cr duplex stainless steels. Scripta Mater. 2006, 55, 991-994. [CrossRef]

16. Tuttle, R. Effect of rare earth additions on grain refinement of plain carbon steels. Int. J. Met. 2012, 6, 51-65. [CrossRef]

17. Dimmock, J.; Freeman, A. Band structure and magnetism of gadolinium metal. Phys. Rev. Lett. 1964, 13, 750. [CrossRef]

18. Holm, M.; Ebel, T.; Dahms, M. Investigations on Ti-6Al-4V with gadolinium addition fabricated by metal injection moulding. Mater. Des. 2013, 51, 943-948. [CrossRef]

19. Ghandvar, H.; Idris, M.H.; Ahmad, N.; Emamy, M. Effect of gadolinium addition on microstructural evolution and solidification characteristics of $\mathrm{Al}-15 \% \mathrm{Mg}_{2} \mathrm{Si}$ in-situ composite. Mater. Charact. 2018, 135, 57-70. [CrossRef]

20. Mangonon, P.L.; Thomas, G. The martensite phases in 304 stainless steel. Metall. Trans. 1970, 1, 1577-1586. [CrossRef]

21. Baddoo, N. Stainless steel in construction: A review of research, applications, challenges and opportunities. J. Constr. Steel Res. 2008, 64, 1199-1206. [CrossRef]

22. Lo, K.H.; Shek, C.H.; Lai, J. Recent developments in stainless steels. Mater. Sci. Eng. R Rep. 2009, 65, 39-104. [CrossRef] 
23. Hashimoto, K.; Asami, K.; Teramoto, K. An X-ray photo-electron spectroscopic study on the role of molybdenum in increasing the corrosion resistance of ferritic stainless steels in HC1. Corros. Sci. 1979, 19, 3-14. [CrossRef]

24. Fujita, N.; Ohmura, K.; Yamamoto, A. Changes of microstructures and high temperature properties during high temperature service of niobium added ferritic stainless steels. Mater. Sci. Eng. A 2003, 351, $272-281$. [CrossRef]

25. Sim, G.M.; Ahn, J.C.; Hong, S.C.; Lee, K.J.; Lee, K.S. Effect of nb precipitate coarsening on the high temperature strength in $\mathrm{Nb}$ containing ferritic stainless steels. Mater. Sci. Eng. A 2005, 396, 159-165. [CrossRef]

26. Zinkle, S.; Maziasz, P.; Stoller, R. Dose dependence of the microstructural evolution in neutron-irradiated austenitic stainless steel. J. Nucl. Mater. 1993, 206, 266-286. [CrossRef]

27. Sourmail, T. Precipitation in creep resistant austenitic stainless steels. Mater. Sci. Technol. 2001, 17, 1-14. [CrossRef]

28. Byun, T.; Hashimoto, N.; Farrell, K. Temperature dependence of strain hardening and plastic instability behaviors in austenitic stainless steels. Acta Mater. 2004, 52, 3889-3899. [CrossRef]

29. Dupoiron, F.; Audouard, J. Duplex stainless steels: A high mechanical properties stainless steels family. Scand. J. Metall. 1996, 25, 95-102.

30. Gunn, R.N. Duplex Stainless Steels: Microstructure, Properties and Applications; Woodhead Publishing: Sawston, UK, 1997.

31. Nilsson Escriba, D.; Materna-Morris, E.; Plaut, R.; Padilha, A. Chi-phase precipitation in a duplex stainless steel. Mater. Charact. 2009, 60, 1214-1219. [CrossRef]

32. Deng, B.; Jiang, Y.; Gao, J.; Li, J. Effect of annealing treatment on microstructure evolution and the associated corrosion behavior of a super-duplex stainless steel. J. Alloys Compd. 2010, 493, 461-464. [CrossRef]

33. Nilsson, J.-O. Super duplex stainless steels. Mater. Sci. Technol. 1992, 8, 685-700. [CrossRef]

34. Sato, Y.; Nelson, T.; Sterling, C.; Steel, R.; Pettersson, C.-O. Microstructure and mechanical properties of friction stir welded SAF 2507 super duplex stainless steel. Mater. Sci. Eng. A 2005, 397, 376-384. [CrossRef]

35. Wharton, J.; Wood, R.; Mellor, B. Wavelet analysis of electrochemical noise measurements during corrosion of austenitic and superduplex stainless steels in chloride media. Corros. Sci. 2003, 45, 97-122. [CrossRef]

36. Nilsson, J.-O.; Karlsson, L.; Andersson, J.-O. Secondary austenite for mation and its relation to pitting corrosion in duplex stainless steel weld metal. Mater. Sci. Technol. 1995, 11, 276-283. [CrossRef]

37. Wei, Z.; Laizhu, J.; Jincheng, H.; Hongmei, S. Effect of ageing on precipitation and impact energy of 2101 economical duplex stainless steel. Mater. Charact. 2009, 60, 50-55. [CrossRef]

38. Yildızl, K. Investigation on the microstructure and toughness properties of austenitic and duplex stainless steels weldments under cryogenic conditions. Mater. Des. 2015, 77, 83-94. [CrossRef]

39. American Society for Testing and Materials. ASTM A890/A890M-91. Standard Practice for Castings, Iron-Chromium-Nickel-Molybdenum Corrosion-Resistant, Duplex (Austenitic/Ferritic) for General Application; ASTM International: West Conshohocken, PA, USA, 1999.

40. Garrison, W.M., Jr.; Wojcieszynski, A.L. A discussion of the effect of inclusion volume fraction on the toughness of steel. Mater. Sci. Eng. A 2007, 464, 321-329. [CrossRef]

41. Bansal, P.; Ardell, A.J. Average nearest-neighbor distances between uniformly distributed finite particles. Metallography 1972, 5, 97-111. [CrossRef]

42. Saeidi, N.; Ekrami, A. Impact properties of tempered bainite-ferrite dual phase steels. Mater. Sci. Eng. A 2010, 527, 5575-5581. [CrossRef]

43. Chao, Y.J.; Ward, J., Jr.; Sands, R.G. Charpy impact energy, fracture toughness and ductile-brittle transition temperature of dual-phase 590 steel. Mater. Des. 2007, 28, 551-557. [CrossRef]

44. Shin, S.Y.; Hwang, B.; Lee, S.; Kim, N.J.; Ahn, S.S. Correlation of microstructure and charpy impact properties in API X70 and X80 line-pipe steels. Mater. Sci. Eng. A 2007, 458, 281-289. [CrossRef]

45. Hwang, B.; Kim, Y.G.; Lee, S.; Kim, Y.M.; Kim, N.J.; Yoo, J.Y. Effective grain size and charpy impact properties of high-toughness X70 pipeline steels. Metall. Mater. Trans. A 2005, 36, 2107-2114. [CrossRef]

46. Zhang, Y.; Ganeev, A.V.; Wang, J.T.; Liu, J.Q.; Alexandrov, I.V. Observations on the ductile-to-brittle transition in ultrafine-grained tungsten of commercial purity. Mater. Sci. Eng. A 2009, 503, 37-40. [CrossRef]

47. Sandsträm, R.; Langenberg, P.; Sieurin, H. Analysis of the brittle fracture avoidance model for pressure vessels in european standard. Int. J. Press. Vessels Pip. 2005, 82, 872-881. [CrossRef] 
48. Chatterjee, A.; Chakrabarti, D.; Moitra, A.; Mitra, R.; Bhaduri, A. Effect of deformation temperature on the ductile-brittle transition behavior of a modified 9Cr-1Mo steel. Mater. Sci. Eng. A 2015, 630, 58-70. [CrossRef]

49. Jeon, S.-H.; Kim, S.-T.; Lee, I.-S.; Park, J.-H.; Kim, K.-T.; Kim, J.-S.; Park, Y.-S. Effects of copper addition on the formation of inclusions and the resistance to pitting corrosion of high performance duplex stainless steels. Corros. Sci. 2011, 53, 1408-1416. [CrossRef]

50. Pan, F.; Zhang, J.; Chen, H.-L.; Su, Y.-H.; Kuo, C.-L.; Su, Y.-H.; Chen, S.-H.; Lin, K.-J.; Hsieh, P.-H.; Hwang, W.-S. Effects of rare earth metals on steel microstructures. Materials 2016, 9, 417. [CrossRef] [PubMed]

51. Wilson, W.; Kay, D.; Vahed, A. The use of thermodynamics and phase equilibria to predict the behavior of the rare earth elements in steel. JOM 1974, 26, 14-23. [CrossRef]

52. Fruehan, R. The effect of zirconium, cerium, and lanthanum on the solubility of oxygen in liquid iron. Metall. Trans. 1974, 5, 345-347. [CrossRef]

53. Choi, J.Y.; Ji, J.H.; Hwang, S.W.; Park, K.-T. Trip aided deformation of a near-Ni-free, Mn-N bearing duplex stainless steel. Mater. Sci. Eng. A 2012, 535, 32-39. [CrossRef]

54. Li, H.; McLean, A.; Rutter, J.; Sommerville, I. Influence of rare earth metals on the nucleation and solidification behavior of iron and 1045 steel. Metall. Trans. B 1988, 19, 383-395. [CrossRef]

55. Kim, S.-T.; Jeon, S.-H.; Lee, I.-S.; Park, Y.-S. Effects of rare earth metals addition on the resistance to pitting corrosion of super duplex stainless steel-Part 1. Corros. Sci. 2010, 52, 1897-1904. [CrossRef]

56. Park, J.H.; Todoroki, H. Control of mgo al2o3 spinel inclusions in stainless steels. ISIJ Int. 2010, 50, $1333-1346$. [CrossRef]

57. Wang, L.; Beckermann, C. Prediction of reoxidation inclusion composition in casting of steel. Metall. Mater. Trans. B 2006, 37, 571-588. [CrossRef]

58. Jeon, S.-H.; Kim, S.-T.; Choi, M.-S.; Kim, J.-S.; Kim, K.-T.; Park, Y.-S. Effects of cerium on the compositional variations in and around inclusions and the initiation and propagation of pitting corrosion in hyperduplex stainless steels. Corros. Sci. 2013, 75, 367-375. [CrossRef]

59. Rice, J.; Johnson, M. Inelastic Behavior of Solids; McGraw-Hill: New York, NY, USA, 1970; p. 641.

60. Oldfield, W. Curve Fitting Impact Test Data: A Statistical Procedure. ASTM Stand. News 1975, $3,11$.

61. Ding, H.-L.; Zhang, T.; Gao, R.; Wang, X.-P.; Fang, Q.-F.; Liu, C.-S.; Suo, J.-P. Low-temperature mechanical and magnetic properties of the reduced activation martensitic steel. Front. Mater. Sci. 2015, 9, $264-271$. [CrossRef]

62. El-Daly, A.; Fawzy, A.; Mansour, S.; Younis, M. Novel SiC nanoparticles-containing Sn-1.0Ag-0.5Cu solder with good drop impact performance. Mater. Sci. Eng. A 2013, 578, 62-71. [CrossRef]

63. Song, H.; Zhu, Q.; Wang, Z.; Shang, J.; Lu, M. Effects of zn addition on microstructure and tensile properties of Sn-1Ag-0.5Cu alloy. Mater. Sci. Eng. A 2010, 527, 1343-1350. [CrossRef]

64. Das, A.; Das, S.K.; Tarafder, S. Correlation of fractographic features with mechanical properties in systematically varied microstructures of cu-strengthened high-strength low-alloy steel. Metall. Mater. Trans. A 2009, 40, 3138. [CrossRef]

65. Lei, W.-S. A framework for statistical modelling of plastic yielding initiated cleavage fracture of structural steels. Philos. Mag. 2016, 96, 3586-3631. [CrossRef]

66. Kumar, S.; Nath, S. Effect of heat input on impact toughness in transition temperature region of weld CGHAZ of a HY 85 steel. J. Mater. Process. Technol. 2016, 236, 216-224. [CrossRef]

67. Yu, J.; Huang, Q.; Wan, F. Research and development on the China low activation martensitic steel (CLAM). J. Nucl. Mater. 2007, 367, 97-101. [CrossRef]

68. Baluc, N.; Gelles, D.; Jitsukawa, S.; Kimura, A.; Klueh, R.; Odette, G.; Van der Schaaf, B.; Yu, J. Status of reduced activation ferritic/martensitic steel development. J. Nucl. Mater. 2007, 367, 33-41. [CrossRef]

69. Dudko, V.; Fedoseeva, A.; Kaibyshev, R. Ductile-brittle transition in a 9\% Cr heat-resistant steel. Mater. Sci. Eng. A 2017, 682, 73-84. [CrossRef] 
70. Kim, M.-C.; Park, S.-G.; Lee, K.-H.; Lee, B.-S. Comparison of fracture properties in SA508 Gr. 3 and Gr. 4N high strength low alloy steels for advanced pressure vessel materials. Int. J. Press. Vessels Pip. 2015, 131, 60-66. [CrossRef]

71. Tanno, T.; Ohtsuka, S.; Yano, Y.; Kaito, T.; Tanaka, K. Effects of manufacturing process on impact properties and microstructures of ODS steels. J. Nucl. Mater. 2014, 455, 480-485. [CrossRef] 